\title{
Effect of Biofield Treatment on Phenotypic and Genotypic Characteristic of Provindencia rettgeri
}

\author{
Mahendra Kumar Trivedi ${ }^{1}$, Shrikant Patil ${ }^{1}$, Harish Shettigar ${ }^{1}$, Khemraj Bairwa ${ }^{2}$ and Snehasis Jana ${ }^{2 *}$ \\ ${ }^{1}$ Trivedi Global Inc., 10624 S Eastern Avenue Suite A-969, Henderson, NV 89052, USA \\ ${ }^{2}$ Trivedi Science Research Laboratory Pvt. Ltd., Hall-A, Chinar Mega Mall, Chinar Fortune City, Hoshangabad Rd., Bhopal- 462026, Madhya Pradesh, India
}

\begin{abstract}
Providencia rettgeri $(P$. rettgeri) is a clinically significant Gram-negative bacterium of genus Providencia, and commonly associated with hospital-acquired infection like urinary tract infection (UTI), gastroenteritis, and ocular infections. Present study was designed to evaluate the effect of biofield treatment on $P$. rettgeri against antimicrobial susceptibility, biochemical reaction pattern, biotype number, and $16 \mathrm{~S}$ rDNA sequence. The samples of $P$. rettgeri (ATCC 9250) were divided into three groups: Gr.I (control), Gr.II (treatment, revived), and Gr.III (treatment, lyophilized). The Gr.II and III were treated with Mr. Trivedi's biofield, and then subsequently characterized for antimicrobial susceptibility, minimum inhibitory concentration (MIC), biochemical reactions, and biotype numbering. The 16S rDNA sequencing was carried out to correlate the phylogenetic relationship of $P$. rettgeri with other bacterial species. The treated cells of P. rettgeri showed an alteration in susceptibility of about $50 \%$ and $53.3 \%$ tested antimicrobials of Gr.II on day 5 and 10 , respectively; and $53.3 \%$ of tested antimicrobials of Gr.III on day 10 . MIC results showed a significant decrease in MIC values of $53.1,56.3$, and $56.3 \%$ antimicrobials in Gr.II on day 5 , Gr.II on day 10 , and Gr.III on day 10 , respectively, as compared to control. The significant changes in biochemical reactions and biotype numbers were also observed in all the treated groups of $P$. rettgeri. Based on nucleotides homology and phylogenetic analysis the $P$. rettgeri was found to be Proteus mirabilis (GenBank Accession Number: AY820623) and nearest homolog species was found to be Proteus vulgaris (Accession No. DQ499636). These findings suggest that biofield treatment can prevent the emergence of absolute resistance of existing antimicrobials to $P$. rettgeri.
\end{abstract}

Keywords: Providencia rettgeri; Biofield treatment; Antimicrobial susceptibility; Biotype; 16S rDNA sequencing

\section{Introduction}

Presently, several microbes have been acquired the resistance to number of antimicrobial agents that were successfully treat the microbial infections earlier. The antimicrobial resistant microbes whether bacteria, fungi, viruses or parasites can survive in regular antimicrobial drugs therapy. The frequent and improper use and misuse of antimicrobial drugs accelerate the emergence of drug-resistant microbes, which were further spread by poor sanitary conditions and meager infection control [1]. Antimicrobial drugs prescribed in nearly all Providencia infections caused by five species: Providencia rettgeri, $P$. alcalifaciens, $P$. rustigianii, $P$. stuartii, and $P$. heimbachae. The $P$. rettgeri is a clinically significant, urease-producing, Gram-negative Bacillus and usually found in both water and land atmospheres. It is generally associated with opportunistic infections in humans such as traveler's diarrhea, urinary tract infections (UTI), skin infection, gastroenteritis, conjunctivitis, and endophthalmitis. The occurrence of $P$. rettger $i$ infection is common throughout the world with $6-33 \%$ of mortality rate, which is even greater in polymicrobial infection $[2,3]$. Recently, $P$. rettgeri has acquired antimicrobial resistance due to producing $\beta$-lactamase enzymes $[4,5]$. Therefore, due to the clinical significance of $P$. rettgeri, development of effective antimicrobial therapy is very needful for human health. As such, no medication is available to cure the resistant strain of microbe but an alternative approach known as biofield treatment is recently reported to alter the antimicrobial sensitivity in different microorganism [6].

The law of mass-energy inter-conversion is existed in the literature for more than 300 years, and the thought was initially reported by Hasenohrl followed by Einstein $[7,8]$. However, the conversion of mass into energy is well established, but its inversion i.e., energy into mass has not yet proven scientifically. Furthermore, the energy can exists in several forms such as kinetic, potential, electrical, magnetic, and nuclear. Similarly, the human nervous system consists the energy in the form of electrical signals $[9,10]$. Thus, human has the ability to harness the energy from environment or universe and can transmit into any leaving or nonliving object(s) around the Globe. The objects always receive the energy and responding into useful way that is called biofield energy and the process is known as biofield treatment. Whenever these electrical signals fluctuate with time, the magnetic field generates as per the Ampere-Maxwell law, and cumulatively known as electromagnetic field. Hence, the electromagnetic field being generated from the human body is known as biofield [11]. Mr. Mahendra Trivedi's biofield treatment has shown to transform the characteristics non-living and living things in several fields such as material science [12-17], agriculture [18-20], and biotechnology $[21,22]$. The biofield treatment has considerably altered the sensitivity of antimicrobials to some microbes $[6,23,24]$.

By conceiving the challenges of antimicrobial resistance in $P$. rettgeri, and advantages of biofield treatment; this work was undertaken to evaluate the effects of biofield treatment on antimicrobials sensitivity, biotype number based on various biochemical reactions, and $16 \mathrm{~S}$ rDNA gene sequencing of $P$. rettgeri.

\section{Materials and Methods}

The sample vial of $P$. rettgeri [American Type Culture Collection (ATCC) 9250] was procured from MicroBioLogics, Inc., USA, and

*Corresponding author: Dr. Snehasis Jana, Trivedi Science Research Laboratory Pvt. Ltd., Hall-A, Chinar Mega Mall, Chinar Fortune City, Hoshangabad Rd., Bhopal- 462026, Madhya Pradesh, India, Tel: +91-755-6660006; E-mail: publication@trivedisrl.com

Received July 03, 2015; Accepted July 20, 2015; Published July 27, 2015

Citation: Trivedi MK, Patil S, Shettigar H, Bairwa K, Jana S (2015) Effect of Biofield Treatment on Phenotypic and Genotypic Characteristic of Provindencia rettgeri. Mol Biol 4: 129. doi:10.4172/2168-9547.1000129

Copyright: ( $) 2015$ Trivedi MK, et al. This is an open-access article distributed under the terms of the Creative Commons Attribution License, which permits unrestricted use, distribution, and reproduction in any medium, provided the original author and source are credited. 
stored as per the suggested storage conditions until further use. The antimicrobial susceptibility, biochemical reactions, and biotype number were evaluated on MicroScan Walk-Away" (Dade Behring Inc., West Sacramento, CA) using Negative Breakpoint Combo 30 (NBPC30) panel. The $16 \mathrm{~S}$ rDNA sequencing study was carried out in Gr. III sample using Ultrapure Genomic DNA Prep Kit; Cat KT 83 (Bangalore Genei, India).

\section{Biofield treatment}

The samples of $P$. rettgeri was divided in three groups: Gr.I (control), Gr.II (treatment, revived), and Gr.III (treatment, lyophilized). Subsequently, the treatment groups (Gr. II and III) were received biofield treatment. The treatment groups were in sealed pack and handed over to Mr. Trivedi for biofield treatment under laboratory condition. Mr. Trivedi provided the treatment through his energy transmission process to the treated groups without touching the samples. Treated samples were assessed for antimicrobial sensitivity, biochemical reactions, and biotyping of $P$. rettgeri. The assays for Gr.II were assessed on day 5 and 10 , and Gr.III was assessed on day 10 . The $16 \mathrm{~S}$ rDNA gene sequencing of $P$. rettgeri was also carried out.

\section{Evaluation of antimicrobial susceptibility of $P$. rettgeri}

Investigation of antimicrobial sensitivity of $P$. rettgeri was carried out with the help of automated instrument, MicroScan WalkAway using Negative Breakpoint Combo 30 (NBPC30) panel, as per the manufacturer's instructions [25]. The minimum inhibitory concentration (MIC) and a qualitative susceptibility like resistant (R), intermediate (I), susceptible (S), or inducible $\beta$-lactamases (IB) were determined by observing the lowest antimicrobial concentration showing growth inhibition [26]. The antimicrobial sensitivity study was carried out using following antimicrobials like amikacin, amoxicillin/ K-clavulanate, ampicillin/sulbactam, ampicillin, aztreonam, cefazolin, cefepime, cefotaxime, cefotetan, cefoxitin, ceftazidime, cefuroxime, ceftriaxone, cephalothin, chloramphenicol, ciprofloxacin, gatifloxacin, gentamicin, imipenem, levofloxacin, meropenem, moxifloxacin, nitrofurantoin, norfloxacin, piperacillin, piperacillin/ tazobactam, tetracycline, ticarcillin, tobramycin, and trimethoprim/ sulfamethoxazole. All these antimicrobials were purchased from Sigma-Aldrich, USA.

\section{Biochemical studies}

The biochemical studies of $P$. rettgeri were performed on MicroScan Walk-Away $[27,28]$. Biochemical reactions patterns were carried out using 32 biochemicals viz. acetamide, adonitol, arabinose, arginine, cetrimide, cephalothin, citrate, colistin, esculin hydrolysis, nitrofurantoin, glucose, hydrogen sulfide, indole, inositol, kanamycin, lysine, malonate, melibiose, nitrate, oxidation-fermentation media, galactosidase, ornithine, oxidase, raffinose, Rhamnose, sorbitol, sucrose, tartarate, tryptophan deaminase, tobramycin, urea, and Voges-Proskauer. All these biochemical were procured from Sigma-Aldrich, USA.

\section{Biotype number}

The biotype numbers of $P$. rettgeri was determined by automated MicroScan Walk-Away processed panel data utilizing biochemical reactions [25].

\section{Amplification and gene sequencing of 16S rDNA}

Genomic DNA was isolated and purified from treated group of $P$. rettgeri cells by using genomic purification Kit, as per the manufacturer's instructions. The $16 \mathrm{~S}$ rDNA gene $(\sim 1.5 \mathrm{~kb})$ was amplified employing universal primers forward 5'AGAGTTTGATCCTGGC-3' and reverse
5'-GGTTACCTTGTTACGACTT-3'. After that, the amplified products were subjected to gel electrophoresis on $1.0 \%$ agarose gel, stained with ethidium bromide, and visualized under UV light in a gel documentation unit (BioRad Laboratories, USA). The amplified fragment of PCR was purified from the agarose gel by DNA Gel Extraction Kit. Sequencing of amplified product was carried out on commercial basis from Bangalore Genei, India. The obtained $16 \mathrm{~S}$ rDNA sequences data were aligned and compared with the sequences, available in Gene Bank database of National Center for Biotechnology Information (NCBI) using the algorithm BLASTn program. The multiple sequence alignment/ phylogenetic tree were constructed using MEGA 3.1 software using neighbour joining method [29].

\section{Results}

\section{Evaluation of antimicrobial susceptibility}

The results of biofield treatment on $P$. rettger $i$ in relation to sensitivity pattern and MIC of tested antimicrobials are summarized in Table 1 and 2, respectively. The biofield treated cells of $P$. rettgeri exhibited an alteration in susceptibility of $50 \%$ and $53.3 \%$ of total antimicrobials in Gr.II on day 5 and 10, respectively; and alteration of $53.3 \%$ of total antimicrobials in Gr.III on $10^{\text {th }}$ day, with about 2-4 folds decrease in the MIC values of respective antimicrobials. Briefly, amikacin, cefepime, chloramphenicol, gentamicin, and tobramycin were converted from

\begin{tabular}{|c|c|c|c|c|c|}
\hline S. No. & Antimicrobial & $\begin{array}{c}\text { Gr.I } \\
\text { Control }\end{array}$ & $\begin{array}{c}\text { Gr.ll } \\
\text { day } 5\end{array}$ & $\begin{array}{c}\text { Gr.ll } \\
\text { day } 10\end{array}$ & $\begin{array}{c}\text { Gr.III } \\
\text { day } 10\end{array}$ \\
\hline 1 & Amikacin & $\mathrm{R}$ & $S$ & $\mathrm{~S}$ & $S$ \\
\hline 2 & Amoxicillin/K-clavulanate & IB & IB & IB & IB \\
\hline 3 & Ampicillin/Sulbactam & 1 & IB & IB & IB \\
\hline 4 & Ampicillin & $\mathrm{R}$ & $\mathrm{R}$ & 1 & IB \\
\hline 5 & Aztreonam & $\mathrm{R}$ & IB & IB & IB \\
\hline 6 & Cefazolin & 1 & IB & IB & IB \\
\hline 7 & Cefepime & $\mathrm{R}$ & $S$ & $S$ & $S$ \\
\hline 8 & Cefotaxime & $\mathrm{R}$ & IB & IB & IB \\
\hline 9 & Cefotetan & $\mathrm{R}$ & IB & IB & IB \\
\hline 10 & Cefoxitin & $\mathrm{R}$ & IB & IB & IB \\
\hline 11 & Ceftazidime & $\mathrm{R}$ & IB & IB & IB \\
\hline 12 & Cefuroxime & $\mathrm{R}$ & IB & IB & IB \\
\hline 13 & Ceftriaxone & IB & IB & IB & IB \\
\hline 14 & Cephalothin & $\mathrm{R}$ & IB & IB & IB \\
\hline 15 & Chloramphenicol & $\mathrm{R}$ & $S$ & $S$ & $S$ \\
\hline 16 & Ciprofloxacin & $S$ & $S$ & $S$ & $S$ \\
\hline 17 & Gatifloxacin & $S$ & $S$ & $S$ & $S$ \\
\hline 18 & Gentamicin & $\mathrm{R}$ & $S$ & $S$ & $S$ \\
\hline 19 & Imipenem & $S$ & S & $\mathrm{S}$ & S \\
\hline 20 & Levofloxacin & $S$ & $S$ & $S$ & $S$ \\
\hline 21 & Meropenem & $S$ & $S$ & $S$ & $S$ \\
\hline 22 & Moxifloxacin & $S$ & $S$ & $S$ & $S$ \\
\hline 23 & Nitrofurantoin & $\mathrm{R}$ & $\mathrm{R}$ & $\mathrm{R}$ & $\mathrm{R}$ \\
\hline 24 & Norfloxacin & $S$ & $S$ & $S$ & $S$ \\
\hline 25 & Piperacillin & IB & IB & IB & IB \\
\hline 26 & Piperacillin/Tazobactam & IB & IB & IB & IB \\
\hline 27 & Tetracycline & $\mathrm{R}$ & $\mathrm{R}$ & $\mathrm{R}$ & $\mathrm{R}$ \\
\hline 28 & Ticarcillin & 1 & IB & IB & IB \\
\hline 29 & Tobramycin & $\mathrm{R}$ & $S$ & $\mathrm{~S}$ & $S$ \\
\hline 30 & Trimethoprim/Sulfamethoxazole & $\mathrm{S}$ & $S$ & $\mathrm{~S}$ & $S$ \\
\hline
\end{tabular}

Gr: Group; I: Intermediate; S: Susceptible; R: Resistant; IB: Reduced Activity of Inducible $\beta$-lactamase

Table 1: Effect of biofield treatment on Providencia rettgeri to susceptibility pattern of selected antimicrobials. 


\begin{tabular}{|c|c|c|c|c|c|}
\hline S. No. & Antimicrobial & $\begin{array}{c}\text { Gr.l } \\
\text { Control }\end{array}$ & $\begin{array}{r}\text { Gr.II } \\
\text { day } 5\end{array}$ & $\begin{array}{c}\text { Gr.II } \\
\text { day } 10\end{array}$ & $\begin{array}{c}\text { Gr.III } \\
\text { day } 10\end{array}$ \\
\hline 1 & Amikacin & $>32$ & $\leq 16$ & $\leq 16$ & $\leq 16$ \\
\hline 2 & Amoxicillin/ K-clavulanate & $\leq 8 / 4$ & $\leq 8 / 4$ & $\leq 8 / 4$ & $\leq 8 / 4$ \\
\hline 3 & Ampicillin/Sulbactam & $16 / 8$ & $\leq 8 / 4$ & $\leq 8 / 4$ & $\leq 8 / 4$ \\
\hline 4 & Ampicillin & $>16$ & $>16$ & 16 & $\leq 8$ \\
\hline 5 & Aztreonam & $>16$ & $\leq 8$ & $\leq 8$ & $\leq 8$ \\
\hline 6 & Cefazolin & 16 & $\leq 8$ & $\leq 8$ & $\leq 8$ \\
\hline 7 & Cefepime & $>16$ & $\leq 8$ & $\leq 8$ & $\leq 8$ \\
\hline 8 & Cefotaxime & $>32$ & $\leq 8$ & $\leq 8$ & $\leq 8$ \\
\hline 9 & Cefotetan & $>32$ & $\leq 16$ & $\leq 16$ & $\leq 16$ \\
\hline 10 & Cefoxitin & $>16$ & $\leq 8$ & $\leq 8$ & $\leq 8$ \\
\hline 11 & Ceftazidime & $>16$ & $\leq 8$ & $\leq 8$ & $\leq 8$ \\
\hline 12 & Cefuroxime & $>16$ & $\leq 4$ & $\leq 4$ & $\leq 4$ \\
\hline 13 & Ceftriaxone & $\leq 8$ & $\leq 8$ & $\leq 8$ & $\leq 8$ \\
\hline 14 & Cephalothin & $>16$ & $\leq 8$ & $\leq 8$ & $\leq 8$ \\
\hline 15 & Chloramphenicol & $>16$ & $\leq 8$ & $\leq 8$ & $\leq 8$ \\
\hline 16 & Ciprofloxacin & $\leq 1$ & $\leq 1$ & $\leq 1$ & $\leq 1$ \\
\hline 17 & Gatifloxacin & $\leq 2$ & $\leq 2$ & $\leq 2$ & $\leq 2$ \\
\hline 18 & Gentamicin & $>8$ & $\leq 4$ & $\leq 4$ & $\leq 4$ \\
\hline 19 & Imipenem & $\leq 4$ & $\leq 4$ & $\leq 4$ & $\leq 4$ \\
\hline 20 & Levofloxacin & $\leq 2$ & $\leq 2$ & $\leq 2$ & $\leq 2$ \\
\hline 21 & Meropenem & $\leq 4$ & $\leq 4$ & $\leq 4$ & $\leq 4$ \\
\hline 22 & Moxifloxacin & $\leq 2$ & $\leq 2$ & $\leq 2$ & $\leq 2$ \\
\hline 23 & Nitrofurantoin & $>64$ & $>64$ & $>64$ & $>64$ \\
\hline 24 & Norfloxacin & $\leq 4$ & $\leq 4$ & $\leq 4$ & $\leq 4$ \\
\hline 25 & Piperacillin & $\leq 16$ & $\leq 16$ & $\leq 16$ & $\leq 16$ \\
\hline 26 & Piperacillin/Tazobactam & $\leq 16$ & $\leq 16$ & $\leq 16$ & $\leq 16$ \\
\hline 27 & Tetracycline & $>8$ & $>8$ & $>8$ & $>8$ \\
\hline 28 & Ticarcillin & 64 & $\leq 16$ & $\leq 16$ & $\leq 16$ \\
\hline 29 & Tobramycin & $>8$ & $\leq 4$ & $\leq 4$ & $\leq 4$ \\
\hline 30 & $\begin{array}{l}\text { Trimethoprim/ } \\
\text { Sulfamethoxazole }\end{array}$ & $\leq 2 / 38$ & $\leq 2 / 38$ & $\leq 2 / 38$ & $\leq 2 / 38$ \\
\hline 31 & ESBL-a Scrn & $>4$ & $\leq 4$ & $\leq 4$ & $\leq 4$ \\
\hline 32 & ESBL-b Scrn & $>1$ & $\leq 1$ & $\leq 1$ & $\leq 1$ \\
\hline
\end{tabular}

Gr: Group; MIC data are presented in $\mu \mathrm{g} / \mathrm{mL}$; ESBL-a, b Scrn: Extended-Spectrum $\beta$-Lactamase Screen

Table 2: Effect of biofield treatment on minimum inhibitory concentration (MIC) of Providencia rettgeri.

resistant (control) to susceptible in treated groups (Gr.II and Gr.III in all assessment). Similarly, cefotetan, cefoxitin, ceftazidime, cefuroxime, cefotaxime, cephalothin, and aztreonam were changed from resistant to inducible $\beta$-lactamase in entire treated groups. The sensitivity of ampicillin was altered from resistant to intermediate and inducible $\beta$-lactamase in Gr.II and III, respectively on day 10. Further, the ampicillin/sulbactam, cefazolin, and ticarcillin were converted from intermediate to inducible $\beta$-lactamase in all the treated groups. The MIC of all the above-mentioned antimicrobials were decreased about 2 -folds except the ticarcillin and cefotaxime that showed about 4 -folds decrease in MIC value.

\section{Organism identification by biochemical reactions}

The biochemical reactions of $P$. rettgeri are reported in Table 3, revealed an alteration in biochemical reaction pattern as $12.1 \%$ of total biochemicals in Gr.II on day 5 and 10 , and $48.5 \%$ of total biochemicals in Gr.III on day 10. Briefly, the cephalothin, kanamycin, and tobramycin biochemical reactions were converted from positive to negative reaction in entire treated groups (Gr.II on day 5 and 10 and Gr.III on day 10). Biochemicals such as arabinose, hydrogen sulfide, lysine, malonate, melibiose, galactosidase, ornithine, raffinose, Rhamnose, sorbitol, sucrose, and Voges-Proskauer were changed from positive to negative reaction only in Gr.III on day 10 with respect to control. Further, tartarate was converted from negative to positive reaction in Gr.II on day 5 only, and tryptophan was converted from negative to positive in Gr.II and Gr.III on day 10, as compared to control.

\section{Effect of biofield treatment on biotype number}

The biotype numbers of $P$. rettgeri was determined on MicroScan Walk-Away processed panel, using biochemical reaction data. The result exhibited alteration in biotype number of $P$. rettger $i$ in the entire treated groups (on all assessment day) as compared to control (Table 4).

\section{$16 \mathrm{~S}$ rDNA gene sequencing}

The $16 \mathrm{~S}$ rDNA sequence was determined in $P$. rettgeri. The

\begin{tabular}{|c|c|c|c|c|c|c|}
\hline S. No. & Code & Biochemical & $\begin{array}{c}\text { Gr.I } \\
\text { Control }\end{array}$ & $\begin{array}{c}\text { Gr.II } \\
\text { day } 5\end{array}$ & $\begin{array}{c}\text { Gr.II } \\
\text { day } 10\end{array}$ & $\begin{array}{c}\text { Gr.III } \\
\text { day } 10\end{array}$ \\
\hline 1 & ACE & Acetamide & - & - & - & - \\
\hline 2 & ADO & Adonitol & + & + & + & + \\
\hline 3 & ARA & Arabinose & + & + & + & - \\
\hline 4 & ARG & Arginine & - & - & - & - \\
\hline 5 & CET & Cetrimide & - & - & - & - \\
\hline 6 & CF8 & Cephalothin & + & - & - & - \\
\hline 7 & CIT & Citrate & + & + & + & + \\
\hline 8 & CL4 & Colistin & + & + & + & + \\
\hline 9 & ESC & Esculin hydrolysis & + & + & + & + \\
\hline 10 & FD64 & Nitrofurantoin & + & + & + & + \\
\hline 11 & GLU & Glucose & + & + & + & + \\
\hline 12 & $\mathrm{H} 2 \mathrm{~S}$ & Hydrogen sulfide & + & + & + & - \\
\hline 13 & IND & Indole & + & + & + & + \\
\hline 14 & INO & Inositol & + & + & + & + \\
\hline 15 & K4 & Kanamycin & + & - & - & - \\
\hline 16 & LYS & Lysine & + & + & + & - \\
\hline 17 & MAL & Malonate & + & + & + & - \\
\hline 18 & MEL & Melibiose & + & + & + & - \\
\hline 19 & NIT & Nitrate & + & + & + & + \\
\hline 20 & OF/G & Oxidation-fermentation & + & + & + & + \\
\hline 21 & ONPG & Galactosidase & + & + & + & - \\
\hline 22 & ORN & Ornithine & + & + & + & - \\
\hline 23 & OXI & Oxidase & - & - & - & - \\
\hline 24 & P4 & Penicillin & + & + & + & + \\
\hline 25 & RAF & Raffinose & + & + & + & - \\
\hline 26 & RHA & Rhamnose & + & + & + & - \\
\hline 27 & SOR & Sorbitol & + & + & + & - \\
\hline 28 & SUC & Sucrose & + & + & + & - \\
\hline 29 & TAR & Tartarate & - & + & - & - \\
\hline 30 & TDA & Tryptophan deaminase & - & - & + & + \\
\hline 31 & TO4 & Tobramycin & + & - & - & - \\
\hline 32 & URE & Urea & + & + & + & + \\
\hline 33 & VP & Voges-Proskauer & + & + & + & - \\
\hline
\end{tabular}

Gr: Group; - (Negative); + (Positive)

Table 3: Effect of biofield treatment on Providencia rettgeri to biochemical reactions.

\begin{tabular}{|l|c|c|c|c|}
\hline Feature & $\begin{array}{c}\text { Gr.I } \\
\text { Control }\end{array}$ & $\begin{array}{c}\text { Gr.ll } \\
\text { day 5 }\end{array}$ & $\begin{array}{c}\text { Gr.II } \\
\text { day 10 }\end{array}$ & $\begin{array}{c}\text { Gr.III } \\
\text { day 10 }\end{array}$ \\
\hline Biotype & 77765376 & 77765374 & 77765774 & 40640644 \\
\hline $\begin{array}{l}\text { Organism } \\
\text { Identification Name }\end{array}$ & P. rettgeri & P. rettgeri & P. rettgeri & P. rettgeri \\
\hline
\end{tabular}

Gr: Group

Table 4: Effect of biofield treatment on Providencia rettgeri to biotype. 
Citation: Trivedi MK, Patil S, Shettigar H, Bairwa K, Jana S (2015) Effect of Biofield Treatment on Phenotypic and Genotypic Characteristic of Provindencia rettgeri. Mol Biol 4: 129. doi:10.4172/2168-9547.1000129

Page 4 of 6

alignment and assessment of the gene sequences data were performed by comparing with the sequences available in gene bank database of NCBI, using the algorithm BLASTn program. The phylogenetic tree was constituted using BLAST-Webpage (NCBI). Based on nucleotides homology and phylogenetic analysis, the Sample 3A (P. rettgeri) showed the genetic similarity with Proteus mirabilis (GenBank Accession Number: AY820623) with 100\% identity of gene sequencing data. Ten different related bacterial species and $P$. rettgeri were considered as Operational Taxonomic Unites (OTUs) in order to investigate the phylogenetic relationship of $P$. rettgeri among other ten related species (Figure 1). Total 1495 base nucleotide of 16S rDNA gene sequences were analysed by multiple alignments using ClustalW of MEGA3.1 program [29]. Numbers of base substitutions per site from pairwise distance analysis between sequences (11 sequences) are shown in Table 5. Based on the phylogenetic tree and 16S rDNA sequencing, the nearest homolog genus-species of $P$. rettgeri was found to be Proteus vulgaris (Accession No. DQ499636). Some other close homologs of $P$. rettgeri can be found from the alignment as indicated in Table 5 .

\section{Discussion}

Discovery of antimicrobial was a turning point in human history that revolutionized medication in several aspects, and saved the countless lives so far. Unfortunately, these wonder drugs have been accompanied by the quick emergence of resistant microbes. The extended spectrum $B$-lactam (ESBL) antibiotics were widely used to cure the severe Gram-negative infections but due to production of extended spectrum $\beta$-lactamases (ESBLs) in the microorganism these ESBL antibiotics are now almost ineffective [30,31]. Similarly, the $P$. rettgeri has also acquired the antimicrobial resistance due to producing of $\beta$-lactamase enzyme and become a considerable threat to the human beings [4].

Research study suggests that most of the clinical isolates of $P$. rettger $i$ were found resistant to older cephalosporin, penicillin, fosfomycin and to antibiotics to which other Enterobacteriaceae species are also resistant [32]. Our experimental control sample (P. rettgeri) showed similar sensitivity and resistant pattern of tested antimicrobials. The treated sample of $P$. rettgeri exhibited the alteration in antimicrobial susceptibility from resistant to susceptible or inducible $\beta$-lactamases. The antimicrobials like amikacin, chloramphenicol, and gentamicin were converted from resistant (control) to susceptible with about 2 -folds decrease in the MIC values. Likewise cefoxitin, ceftazidime, cephalothin, and aztreonam were converted from resistant to inducible $\beta$-lactamase, in entire treated groups with about 2 -folds decrease in the MIC values. The highest decrees (i.e., 4 -folds) in MIC value were observed for cefotaxime and ticarcillin in the entire treated sample. Overall, different class of antimicrobials showed significant effect after

\begin{tabular}{c|c|ccccccccccc}
\hline \multicolumn{1}{c}{ AN } & & 1 & 2 & 3 & 4 & 5 & 6 & 7 & 8 & 9 & 10 & 11 \\
\hline DQ499636 & 1 & - & 0.981 & 0.993 & 0.964 & 0.992 & 0.963 & 0.991 & 0.951 & 0.948 & 0.992 & 0.991 \\
DQ885259 & 2 & 0.019 & - & 0.983 & 0.963 & 0.983 & 0.962 & 0.982 & 0.957 & 0.953 & 0.985 & 0.982 \\
AF008582 & 3 & 0.007 & 0.017 & - & 0.962 & 0.992 & 0.960 & 0.998 & 0.954 & 0.951 & 0.992 & 0.998 \\
DQ205449 & 4 & 0.036 & 0.037 & 0.038 & - & 0.961 & 0.999 & 0.960 & 0.949 & 0.947 & 0.962 & 0.960 \\
DQ885262 & 5 & 0.008 & 0.017 & 0.008 & 0.039 & - & 0.960 & 0.990 & 0.951 & 0.948 & 0.999 & 0.990 \\
DQ205448 & 6 & 0.037 & 0.038 & 0.040 & 0.001 & 0.040 & - & 0.959 & 0.948 & 0.945 & 0.960 & 0.959 \\
AY820623 & 7 & 0.009 & 0.018 & 0.002 & 0.040 & 0.010 & 0.041 & - & 0.952 & 0.948 & 0.991 & 1.000 \\
AM040489 & 8 & 0.049 & 0.043 & 0.046 & 0.051 & 0.050 & 0.052 & 0.048 & - & 0.988 & 0.951 & 0.952 \\
AM040490 & 9 & 0.052 & 0.047 & 0.050 & 0.053 & 0.052 & 0.055 & 0.052 & 0.013 & - & 0.948 & 0.948 \\
DQ885257 & 10 & 0.008 & 0.015 & 0.008 & 0.038 & 0.001 & 0.040 & 0.009 & 0.050 & 0.052 & - & 0.991 \\
Sample 3A & 11 & 0.009 & 0.018 & 0.002 & 0.040 & 0.010 & 0.041 & 0.000 & 0.048 & 0.052 & 0.009 & - \\
\hline AN, GenBank Accession Number & & & & & & & & &
\end{tabular}

Figure 1: Distance matrix based on nucleotide sequence homology (Using Kimura-2 Parameter).

\begin{tabular}{|c|c|c|c|}
\hline Alignment View & ID & Alignment results & Sequence description \\
\hline $\mathrm{III}$ & $3 \mathrm{~A}$ & 0.93 & Sample studied \\
\hline 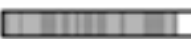 & AY820623 & 0.93 & Proteus mirabilis \\
\hline 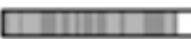 & AF008582 & 0.94 & Proteus mirabilis \\
\hline T. & DQ499636 & 0.94 & Proteus vulgaris \\
\hline 1111 & DQ885262 & 0.98 & Proteus hauseri strain NCTC 4175 \\
\hline 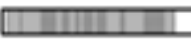 & DQ885257 & 0.98 & Proteus vulgaris strain ATCC 29905 \\
\hline IIII & DQ885259 & 0.92 & Proteus myxofaciens strain NCIMB 13273 \\
\hline TII & DQ205449 & 0.9 & Xenorhabdus hominickii strain KR05 \\
\hline 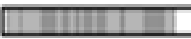 & DQ205448 & 0.89 & Xenorhabdus hominickii strain KR01 \\
\hline \begin{tabular}{|l|l|} 
\\
\end{tabular} & AM040489 & 0.93 & Providencia rustigianii type strain DSM 4541 \\
\hline 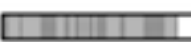 & AM040490 & 0.88 & Providencia heimbachae type strain DSM 3591 \\
\hline
\end{tabular}

Table 5: The closest sequences of Providencia rettgeri from sequence alignment using NCBI GenBank and ribosomal database project (RDP). 
Citation: Trivedi MK, Patil S, Shettigar H, Bairwa K, Jana S (2015) Effect of Biofield Treatment on Phenotypic and Genotypic Characteristic of Provindencia rettgeri. Mol Biol 4: 129. doi:10.4172/2168-9547.1000129

Page 5 of 6

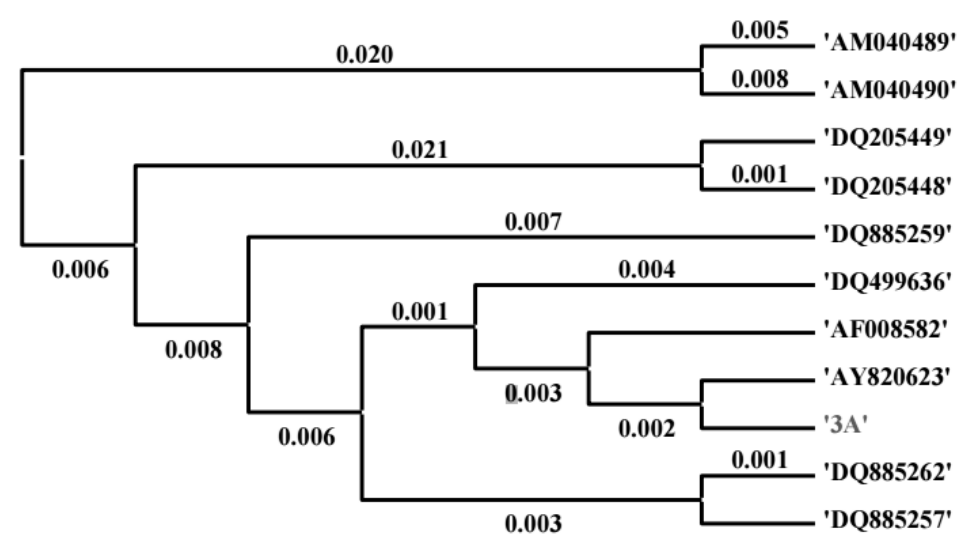

Figure 2: Phylogenetic tree of the partial 16S rDNA gene sequencing using MEGA 3.1 software by Neighbor joining method.

biofield treatment viz. $\beta$-Lactam penicillin (ampicillin/sulbactam), cephalosporin (cefazolin, cefepime, cefotetan, and cefuroxime), monobactum (azetronan), and aminoglycosides (tobramycin and amikacin). In addition, the treated sample of $P$. rettger $i$ also showed the considerable alteration in biochemical reactions patterns. The biotype number of $P$. rettgeri was also changed from 77765376 (control) to 7776 5374, 7776 5774, in Gr.II on day 5 and 10, respectively, and 40640644 in Gr.III on day 10 (Table 4). Based on the BLASTn analysis, the sample 3 A was identified as $P$. mirabilis with $100 \%$ similarity in gene sequence. The phylogenetic tree diagram (Figure 2) anticipated the closest species of $P$. rettgeri to be as Proteus vulgari. The present study revealed that biofield treatment could alter the sensitivity of antimicrobials against $P$. rettgeri. Based on these results, it seems that biofield treatment can be a better alternate of existing drug therapy in future.

\section{Conclusions}

Altogether, these results suggest that Mr. Trivedis biofield treatment has a significant impact on antimicrobial susceptibility, MIC value, biochemical reactions pattern, and biotype number of $P$. rettgeri.

\section{Acknowledgement}

Authors gratefully acknowledged the whole team of PD Hinduja National Hospital and MRC, Mumbai, Microbiology Lab for their support.

\section{Reference}

1. WHO (2014) Antimicrobial resistance.

2. Armbruster CE, Smith SN, Yep A, Mobley HL (2014) Increased incidence of urolithiasis and bacteremia during Proteus mirabilis and Providencia stuarti coinfection due to synergistic induction of urease activity. J Infect Dis 209: 1524-1532.

3. Yoh M, Matsuyama J, Ohnishi M, Takagi K, Miyagi H, et al. (2005) Importance of Providencia species as a major cause of travelers' diarrhea. J Med Microbiol 54: 1077-1082

4. Tada T, Miyoshi-Akiyama T, Dahal RK, Sah MK, Ohara H, et al. (2014) NDM-1 Metallo- $\hat{I}^{2}$-Lactamase and ArmA $16 \mathrm{~S}$ rRNA methylase producing Providencia rettgeri clinical isolates in Nepal. BMC Infect Dis 14: 56.

5. Chiaretto G, Perin R, Bettini F, Sturaro A, Carro M, et al. (2007) E. coli, K. pneumoniae and Providencia rettgeri ESBLs producing isolated from pigs in the Veneto region, Italy. 7th International Symposium on the Epidemiology and Control of Foodborne Pathogens in Pork. 425-428.

6. Trivedi MK, Patil S (2008) Impact of an external energy on Staphylococcus epidermis [ATCC-13518] in relation to antibiotic susceptibility and biochemical reactions-an experimental study. J Accord Integr Med 4: 230-235.

7. Hasenohrl F (1904) On the theory of radiation in moving bodies. Ann Phys 15: 344-370.

8. Einstein A (1905) Does the inertia of a body depend upon its energy-content. Ann Phys 18: 639-641.
9. Becker RO, Selden G (1985) The body electric: Electromagnetism and the foundation of life, William Morrow and Company Inc., New York, 113-118.

10. Barnes RB (1963) Thermography of the Human Body. Science 140: 870-877.

11. Rubik B (2002) The biofield hypothesis: Its biophysical basis and role in medicine. J Altern Complement Med 8: 703-717.

12. Trivedi MK, Tallapragada RR (2009) Effect of super consciousness external energy on atomic, crystalline and powder characteristics of carbon allotrope powders. Mater Res Innov 13: 473-480.

13. Trivedi MK, Patil S, Tallapragada RM (2012) Thought intervention through biofield changing metal powder characteristics experiments on powder characterization at a PM Plant. Future Control and Automation Lecture Notes in Electrical Engineering 2: 247-252.

14. Trivedi MK, Patil S, Tallapragada RM (2013) Effect of biofield treatment on the physical and thermal characteristics of vanadium pentoxide powders. J Mater Sci Eng S11: 001.

15. Trivedi MK, Patil S, Tallapragada RM (2013) Effect of bio field treatment on the physical and thermal characteristics of silicon, tin and lead powders. J Material Sci Eng 2: 125.

16. Trivedi MK, Patil S, Tallapragada RM (2014) Atomic, crystalline and powder characteristics of treated zirconia and silica powders. J Mater Sci Eng 3: 144.

17. Trivedi MK, Patil S, Tallapragada RMR (2015) Effect of biofield treatment on the physical and thermal characteristics of aluminium powders. Ind Eng Manage 4: 151.

18. Shinde V, Sances F, Patil S, Spence A (2012) Impact of biofield treatment on growth and yield of lettuce and tomato. Aust J Basic Appl Sci 6: 100-105.

19. Sances F, Flora E, Patil S, Spence A, Shinde V (2013) Impact of biofield treatment on ginseng and organic blueberry yield. Agrivita J Agric Sci 35.

20. Lenssen AW (2013) Biofield and fungicide seed treatment influences on soybean productivity, seed quality and weed community. Agricultural Journa 8: 138-143.

21. Patil SA, Nayak GB, Barve SS, Tembe RP, Khan RR (2012) Impact of biofield treatment on growth and anatomical characteristics of Pogostemon cablin (Benth.). Biotechnology 11: 154-162.

22. Altekar N, Nayak G (2015) Effect of biofield treatment on plant growth and adaptation. J Environ Health Sci 1: 1-9.

23. Trivedi MK, Patil S (2008) Impact of an external energy on Yersinia enterocolitica [ATCC-23715] in relation to antibiotic susceptibility and biochemical reactions: An experimental study. Internet J Alternat Med 6.

24. Trivedi MK, Bhardwaj Y, Patil S, Shettigar $\mathrm{H}$, Bulbule, A (2009) Impact of an external energy on Enterococcus faecalis [ATCC-51299] in relation to antibiotic susceptibility and biochemical reactions-an experimental study. J Accord Integr Med 5: 119-130.

25. Fader RC, Weaver E, Fossett R, Toyras M, Vanderlaan J, et al. (2013) Multilaboratory study of the biomic automated well-reading instrument versus MicroScan WalkAway for reading MicroScan antimicrobial Susceptibility and identification panels. J Clin Microbiol 51: 1548-1554. 
Citation: Trivedi MK, Patil S, Shettigar H, Bairwa K, Jana S (2015) Effect of Biofield Treatment on Phenotypic and Genotypic Characteristic of Provindencia rettgeri. Mol Biol 4: 129. doi:10.4172/2168-9547.1000129

26. Gomaa FM, Tawakol WM, Abo El-Azm FI (2014) Phenotypic and genotypic detection of some antimicrobial resistance mechanisms among multidrugresistant Acinetobacter baumannii isolated from immunocompromised patients in Egypt. Egypt J Med Microbiol 23: 99-111.

27. Jorgensen JH, Ferraro MJ (2009) Antimicrobial susceptibility testing: A review of general principles and contemporary practices. Clin Infect Dis 49: 17491755.

28. Lennox VA, Ackerman VP (1984) Biochemical identification of bacteria by replicator methods on agar plates. Pathology 16: 434-440.

29. Kumar S, Tamura K, Nei M (2004) MEGA3: Integrated software for Molecular Evolutionary Genetics Analysis and sequence alignment. Brief Bioinform 5: 150-163.
30. Eftekhar F, Rastegar M, Golalipoor M, Mansoursamaei N (2012) Detection of Extended Spectrum B-Lactamases in Urinary Isolates of Klebsiella pneumoniae in Relation to Bla, Bla and Bla Gene Carriage. Iran J Public Health 41: 127-132.

31. Rakotonirina HC, Garin B, Randrianirina F, Richard V, Talarmin A, et al (2013) Molecular characterization of multidrug-resistant extended-spectrum B-lactamase-producing Enterobacteriaceae isolated in Antananarivo, Madagascar. BMC Microbiol 13: 1-10.

32. Stock I, Wiedemann B (1998) Natural antibiotic susceptibility of Providencia stuartii, $P$. rettgeri, $P$. alcalifaciens and $P$. rustigianii strains. J Med Microbio 47: 629-642. 